$(F=37.6, \mathrm{df}=4 / 24, \mathrm{p}>.001$, and $F=14.29, \mathrm{df}=9 / 54$, $\mathrm{p}>.001$, respectively). one interaction term, i.e., B by $\mathrm{C}$ was also significant $(F=2.094, \mathrm{df}=36 / 216, \mathrm{p}>.001)$.

These results are clearly consistent with the results indicated in Fig. 1 and Table 1. There were wide disparities in the mean percent recall for the various numbers ranging from $82.5 \%$ for Number 2 to $11.25 \%$ for Number 0. A Tukey-type multiple range test was performed to determine which numbers were different in information processing. The number 0 was far nww difficult to recognize than any other number. There was no major evidence of differences in recognition between the five most easily recognized numbers $(2,4,5,7,1)$, which are all significantly more recognizable than the four numbers that are hardest to recognize $(9,8,6,0)$. These differences between numbers replicate the results of Mayzner (1972) with letters, and provide further evidence that would seem to be difficult to account for by either integration or interruption theory.

The interacting effect of on-time and numbers can be seen by an examination of Table 1 and Fig. 1 . It can be seen clearly that the increase in recognition for increasing on-time is by no means constant for all numbers. The numbers $2,4,5$, and 7 improve their recognition rapidly with increasing on-time. The number 1 needs more processing time to achieve high recognition. The numbers which are most difficult to recognize $(6,8,0)$ are much slower in improving their recognition for increased on-time. For example, the number 8 almost reaches a recognition score of only $50 \%$ after $20 \mathrm{msec}$ on-time, while the number 0 surpasses chance levels only with an on-time of $20 \mathrm{msec}$. These results, by replicating the result of Mayzner (1972), suggest that the pattern recognition subroutines for numbers as well as letters are different for each alphanumeric character.

These pattern-recognition subroutines can be further investigated by analyzing the matrix of errors for each stimulus-response pair provided in Table 2 . This matrix of stimuli and responses is not a symmetric matrix. Two numbers are not confused with each other regardless of stimulus and response. For example, Ss are more apt to respond with 2 when a 7 is presented than to respond with 7 when 2 is shown. Symmetry of confusion appears to be highly lacking for approximately $40 \%$ of the stimulus-response pairs. This suggests that only certain features on the number may be detected in the time available, thereby creating confusions with other numbers having similar components.

Finally, Mayzner (1972) has suggested that different Ss show high degrees of similarity in their orderings of letter-recognition scores. In the current study, the consistency of the ordering of the letters was measured by Kendall's coefficient of concordance (W). For this sample of eight Ss, W was highly significant $\left(0.677 ; \chi^{2}\right.$ $=4 \$ 744, \mathrm{df}=9, \mathrm{p}>.001)$. This $\mathrm{r}+$ ult gives further evidence iv the suggestion that all Ss are using similar processing subroutines at varying processing rates. The difference between Ss may be due to varying execution rates and not be a function of the set of subroutines utilized.

\section{REFERENCES}

Edwards, A. L. Experimental design in psychological research. New York: Holt, Rinehart, \& Winston, 1968.

Ericksen, C. W \& Collins, J. F. Backward masking in vision Psychonomic Science, 1964, 1, 101-102.

Kahneman, D. Methods, findings and theory in studies of visual masking. Psychological Bulletin, 1968, 70, 404-425.

Kinsbourne, M., \& Warrington, E. K. The effect of an after-coming random pattern on the perception of brief visual stimuli. Quarterly Journal of Experimental Psychology, 1962, 14, 223-234.

Mayzner, M. S. The research potential of a computer-based cathode-ray tube display system. Behavior Research Methods \& Instrumentation, 1968, 1, 41-43.

Mayzner, M. S. Visual information processing of alphabetic inputs. Psychonomic Monograph Supplements, 1972, 4, 239-243.

Mayzner, M. S., \& Greenberg, J. Studies in the processing of sequentially presented inputs with overprinting paradigms. Psychonomic Monograph Suppliments, 1971, 4, 73-84.

Mayzner, M. S. \& Tresselt, M. E. Visual information processing with sequential inputs: A general model for sequential blanking, displacement and overprinting phenomena. Annals of the New Y ork Academy of Sciences, 1970, 169, 599-618.

Mayzner, M. S. Tresselt, M. E., \& Helfer, M. S. A research strategy for studying certain effects of very fast sequential inputs on the visual system. Psychonomic Monograph Supplements, 1967a, 2, 73-81.

Mayzner, M. S., Tresselt, M. E., \& Helfer, M. S. A provisional model of visual information processing with sequential inputs. Psychonomic Monograph Supplements, 1967b, 2, 91-108.

Siegel, S. Nonparametric statistics for the behavioral sciences. New York: McGraw-Hill, 1956.

Sperling, G. Successive approximations to a model for short term memory. Acta Psychologica, 1967, 27, 285-292.

Uttal, W. R. Masking of alphabetic character recognition by dynamic visual noise (DVN). Perception \& Psychophysics, 1969, 6, 121-128.

Winer, B. J. Statistical principles in experimental design. New York: McGraw-Hill, 1962.

(Received for publication April 16, 1973.)

\title{
Recovery from punishment related to movement and punishment severity
}

\author{
JOHN H. HULL \\ Kent State University, Kent, Ohio 44242 \\ and \\ HENRY E. KLUGH \\ Alma College, Alma, Mich. 48801
}

Thirty-two Sprague-Dawley rats were punished for barpressing, using two intensities orthogonal to two durations of shock, until a 5-min nonresponse criterion was reached. Speed of recovery was significantly correlated with proximity to the response manipulandum during the nonresponse criterion period, but independent of the intensity and duration of shock used. Intensity and duration of shock combine to determine severity of punishment. 


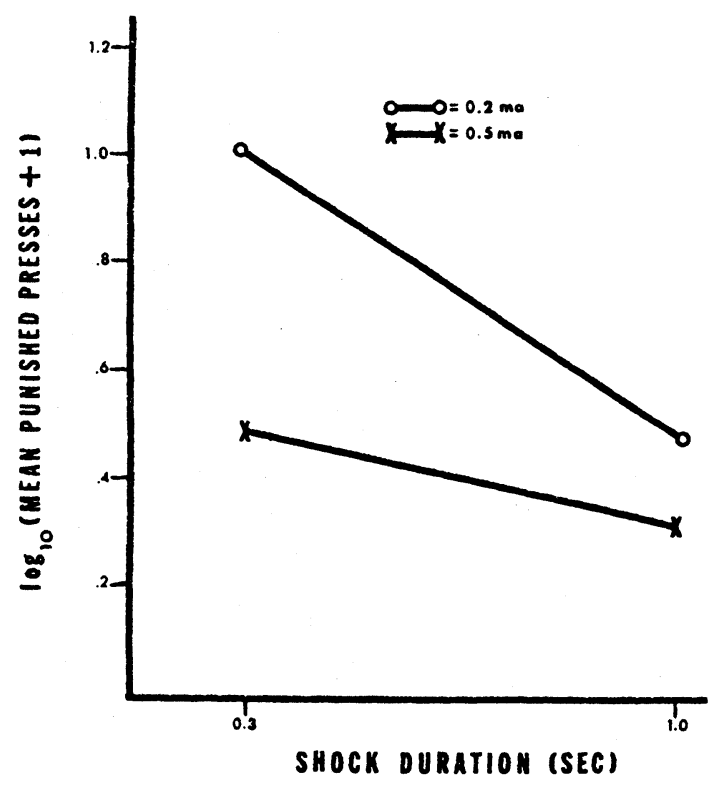

Fig. 1. Number of punished presses to a 5-min nonresponse criterion as a function of experimental group.

Recent studies have examined some of the parameters of punishment as they affect response suppression. However, few have examined the variables which influence recovery from punishment. Hall (1955) found a significant positive correlation between activity and extinction of anxiety, and Liddell (1964) reported that greater activity was related to more rapid recovery from the effects of punishment. Observations of many $(\mathrm{N}>100)$ rats punished to a nonresponse criterion and then allowed to recover indicated that rats typically retreated from the bar and then froze in the half of the box away from the bar and dipper. During recovery from punishment, the rats would approach the bar and dipper gradually, spending a progressively greater proportion of time in the half of the box containing the bar and dipper. It was therefore hypothesized that the amount of time spent in the half of the box away from the bar and dipper during the nonresponse criterion period would correlate positively with slower recovery times, as measured from the beginning of the nonresponse criterion period to the first nonpunished barpress during recovery.

Church, Raymond, \& Beauchamp (1967) reported that shock duration and intensity combine to determine the severity of punishment. It was therefore hypothesized that bar-trained rats, when punished at different intensities and durations of shock, would require different numbers of presses to reach a nonresponse criterion. Boe (1966) found that the amount of recovery from punishment depends on the degree of punishment-induced suppression in response strength. Hence, if the same nonresponse criterion of response suppression is used with rats given different shock intensities and durations, it is predicted that recovery for all groups will occur within equivalent time spans.

\section{METHOD \\ Subjects}

Ss were 32 experimentally naive male Sprague-Dawley rats, each weighing $250-300 \mathrm{~g}$. All rats were housed in pairs under conditions of 24-h artificial illumination. Purina Rat Chow was available to Ss continuously in their home cages. All Ss were put on a 23-h deprivation schedule at least a week before the experiment began.

\section{Apparatus}

All experimental trials used the same Lafayette Instrument Co. Model A632 Skinner box. The section of the box containing the bar and dipper will be referred to as the "front half" of the box; the section farthest from the bar and dipper will be called the "back half." The box was $30.5 \mathrm{~cm}$ long, with the front and back halves clearly marked.

Shock was provided by a Lafayette Instrument Co. Model A615A shock source through a Scientific Prototype mechanical shock scrambler. Duration of shock was controlled by a Giannini Controls Corporation Model 240A timer, calibrated to the nearest $0.1 \mathrm{sec}$. Other time intervals were measured with stopwatch accuracy.

\section{Procedure}

Ss were assigned randomly to one of the four experimental conditions. These conditions included two intensities of shock, 0.2 and $0.5 \mathrm{~mA}$, orthogonal to two durations of shock, 0.3 and $1.0 \mathrm{sec}$.

Two days before their experimental trials, Ss were bar-trained to a criterion of approximately 200 continuously reinforced barpresses. Ss were returned to their home cages, given 10-min access to water, then deprived of water for $24 \mathrm{~h}$. After this deprivation, all rats were run to a criterion of 100 continuously

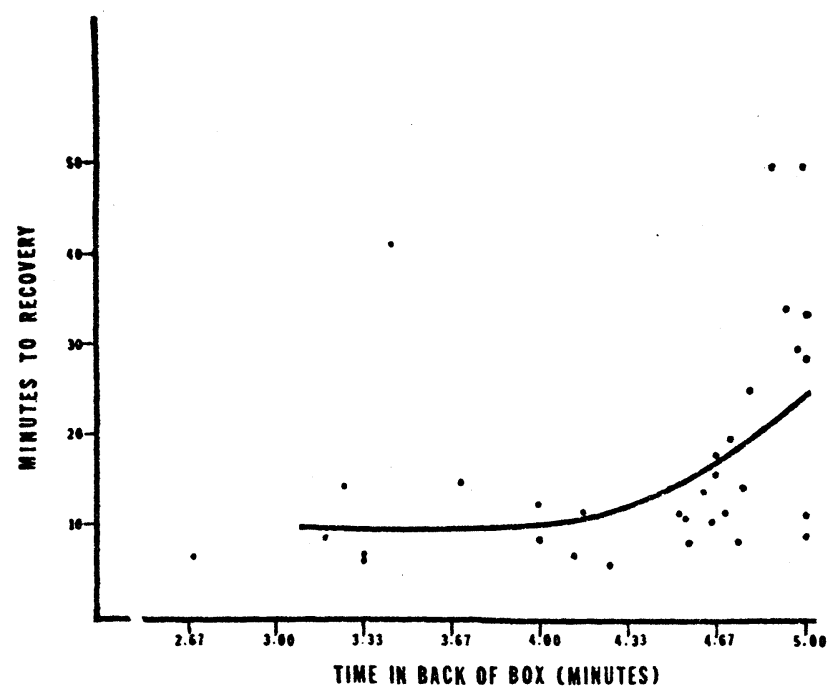

Fig. 2. Scatterplot of recovery time related to time in the back half of the box during the nonresponse criterion period, with least squares curve of best fit. 
reinforced barpresses, then returned to their home cages for $24 \mathrm{~h}$, without being given any additional water.

$O n$ the punishment day, $S$ was given continuous reinforcement until he made the 30th barpress. All rats reached a rate of at least 10 presses/min during this time. After the 30 th press occurred, all subsequent presses produced both shock and water reinforcement until the 5-min nonresponse criterion was reached. During the 5-min nonresponse period, E recorded the amount of time $S$ spent in the back half of the cage. $S$ was considered to be in the back half of the box when over one-half of his body length, excluding his tail, was in this section.

After $\mathrm{S}$ met the nonresponse criterion, subsequent barpresses produced water but no shock. Time for S's first recovery response was recorded, beginning from the last shocked barpress. A maximum of $50 \mathrm{~min}$ was provided for this response to occur. Two Ss did not recover within $50 \mathrm{~min}$.

\section{RESULTS}

A 2 by 2 analysis of variance, using numbers of punished presses to the nonresponse criterion and corrected for heterogeneity of variance by a $\log (\mathrm{X}+1)$ transformation, showed significant between intensities $(\mathrm{F}=17.07, \mathrm{df}=1,28, \mathrm{p}<.001)$ and between durations $(\mathrm{F}=14.30, \mathrm{df}=1,28, \mathrm{p}<.001)$ of shock effects. The interaction of Shock Intensity by Duration did not reach significance at the .05 level $(F=2.94$, df $=1,28$, $\mathrm{p}>.05$ ). Figure 1 shows the relationships of punishment intensity and duration to numbers of punished presses for the four groups.

Only one $\mathrm{S}$ made more than 10 punished presses, and no $S$ made more than 50 . Thus, no $S$ received more than 80 reinforcements during the punishment day. Ss with similar amounts of water deprivation will typically make several hundred presses in the time it took to complete the punishment sessions. It is therefore highly unlikely that the nonresponse of any $S$ was due to satiation rather than to the effects of punishment, or that recovery of responding was due to recovery from temporary thirst satiation.

Because four Ss spent the entire $5 \mathrm{~min}$ of the nonresponse criterion period in the back half of the box and two Ss did not recover within the 50-min time limit, a rho correlation for pooled Ss was calculated between time spent in the back half of the box during the nonresponse criterion period and time until the first recovery press. The resulting correlation was statistically significant $(\rho=.52, \mathrm{df}=30, \mathrm{p}<.01)$. A quadratic regression analysis, which included the arbitrary data points represented by maximum values of time spent in the back half of the box and time to recovery, showed the relationship to be curvilinear. Figure 2 includes a scatterplot of data points and a least squares quadratic curve of best fit.

A Kruskal-Wallis analysis of variance was used to test the differences among times to the first recovery press for the four groups. The chi-square value obtained was not significant $\left(\chi^{2}=1.96, \mathrm{df}=3, \mathrm{p}>.50\right)$. Another Kruskal-Wallis analysis of variance among times spent in the back half of the box during the nonresponse period
Table 1

Summary of Recovery Data

\begin{tabular}{cccccc}
\hline & \multicolumn{2}{c}{$\begin{array}{c}\text { Time (Sec) in Back of } \\
\text { Box During Recovery }\end{array}$} & \multicolumn{2}{c}{$\begin{array}{c}\text { Time (Sec) to First } \\
\text { Nonpunished Press }\end{array}$} \\
\cline { 2 - 3 } \cline { 5 - 6 } Group & Median & Range & & Median & Range \\
\hline $0.3 \mathrm{sec}, 0.2 \mathrm{~mA}$ & 239.5 & $163-300$ & & 701.5 & $326-2503$ \\
$1.0 \mathrm{sec}, 0.2 \mathrm{~mA}$ & 281.0 & $248-300$ & & 664.0 & $395-2042$ \\
$0.3 \mathrm{sec}, 0.5 \mathrm{~mA}$ & 275.5 & $191-300$ & 676.5 & $417-3000+$ \\
$1.0 \mathrm{sec}, 0.5 \mathrm{~mA}$ & 286.5 & $200-300$ & 864.0 & $365-3000+$ \\
\hline
\end{tabular}

for the four groups produced a nonsignificant chi square $\left(\chi^{2}=4.62, \mathrm{df}=3, \mathrm{p}>.10\right)$. Group medians and ranges of the values used in the Kruskal-Wallis analyses are presented in Table 1.

\section{DISCUSSION}

When a nonresponse criterion of severity of punishment was used, higher intensity or longer duration of shock resulted in fewer barpresses before a nonresponse criterion was reached. This finding is congruent with the Church, Raymond, \& Beauchamp (1967) observation that duration and intensity of shock combine to determine the severity of punishment.

The significant correlation between time spent in the back half of the box during the nonresponse period and time to the first barpress following the nonresponse period for the pooled Ss indicated that recovery from punishment is related to the movement of $S$ during the nonresponse period. No causality can be inferred from this correlation. However, regardless of the intensity and duration of punishment used, Ss which spent more time near the bar and dipper tended to recover faster.

All rats were carefully observed throughout the course of the experiment, and several common behaviors were noted. All Ss showed approach-avoidance behavior toward the bar and dipper after the beginning of the punished trials. After their last punished presses, all Ss showed some oscillatory behavior toward the bar and/or dipper, then retreated to the back of the box, where they typically froze for varying lengths of time. None of these behaviors were noted during the minutes of reinforcement immediately preceding punishment.

After a period of freezing and limited movement, all rats again exhibited approach-avoidance toward the front half of the box. All Ss, upon making first barpresses during recovery, showed distinct startle responses and jumped backwards away from the bar. Some Ss immediately retreated to the back half of the box and froze for the last $5 \mathrm{~min}$, during which observations were made. The rest showed oscillatory behavior toward the bar and dipper, and generally made additional presses during that 5-min period.

It was noted that all Ss retreated to the back half of the box during the punishment trials. Work is presently being done to determine how important forced movement is in determining the rate of recovery.

\section{REFERENCES}

Boe, E. E. Effect of punishment duration and intensity on the extinction of an instrumental response. Journal of Experimental Psychology, 1966, 72, 125-131.

Church, R. M., Raymond, G. A., \& Beauchamp, R. D. Response suppression as a function of intensity and duration of a punishment. Journal of Comparative \& Physiological Psychology, 1967, 63, 39-44.

Hall, J. C. Some conditions of anxiety extinction. Journal of Abnormal \& Social Psychology, 1955, 51, 126-132.

Liddell, H. S. The challenge of Pavlovian conditioning and experimental neuroses in animals. In $J$. Wolpe (Ed.), The conditioning therapies. New York: Holt, Rinehart \& Winston, 1964.

(Received for publication March 28, 1973.) 